\title{
TABLE ERRATUM
}

583.-H. B. Dwight, Tables of Integrals and Other Mathematical Data, 4th ed., Macmillan, New York, 1961.

On page 231, the conditions on the parameters in formula 860.39 should read $a>0, p>1$. Similarly, on the following page, the conditions on the parameters in formula 860.49 should read $a>0, p>0, p \neq 1$.

HenRY E. FetTIS

1885 California, Apt. 62

Mountain View, California 94041

EDrtorual NOTE: For an identification of further errors in this edition, see Math. Comp., v. 16, 1962, p. 405, MTE 313. 